\title{
THE INTERNET AT THE SERVICE OF SOCIETY: BUSINESS ETHICS, RATIONALITY, AND RESPONSIBILITY
}

\author{
INTERNET AL SERVICIO DE LA SOCIEDAD: \\ ÉTICA EMPRESARIAL, RACIONALIDAD Y \\ RESPONSABILIDAD
}

\author{
Wenceslao J. GonZalez \\ Center for Research in Philosophy of Science and Technology, \\ University of A Coruña
}

AвSTRACT: Serving the community is what the Internet - in the broad sense does in many ways, within the knowledge society. The layers of its ontological structure - technology infrastructure, the Web, and the cloud computing, practical applications (apps), and the "mobile Internet" - are in principle at the service of society. This service is carried out by companies, which are ethically assessable insofar as they are "social subjects." Their public service purpose at the three layers during the coronavirus lockdown is considered here.

Within a framework of business ethics, this article looks deeply at companies as "social subjects." They contribute decisively to a multilayered reality that reaches half of the world's population. The analysis of this network of networks is carried out through

\footnotetext{
* Professor of Logic and Philosophy of Science; Faculty of Humanities and Information Science; University of A Coruña; Dr Vazquez Cabrera street, w/n; 15403-Ferrol (A Coruña). E-Mail: wenceslao.gonzalez@udc.es
} 
rationality and responsibility. Thus, this paper analyzes its ethical responsibility based on the social ontology of business firms and the ethical problems according to the kind of rationality involved in the companies - micro, meso, or macro - in accordance with their goals. Then, from the perspective of service to society, this study reflects on business ethics of the Internet — in the broad sense — in two directions: 1) the need for evaluative rationality or rationality of ends, because instrumental rationality or rationality of means is insufficient for ethics, and 2) the importance of combining individual responsibility with social responsibility.

KEYwORDs: Internet, Web, cloud computing, apps, "mobile Internet," public service, society, business ethics, rationality, and responsibility.

Resumen: Servir a la comunidad es lo que Internet — en sentido amplio - hace de muchas maneras, dentro de la Sociedad del Conocimiento. Las capas de su estructura ontológica - la infraestructura tecnológica, la Web y la nube, las aplicaciones prácticas (apps) e "Internet móvil" - están, en principio, al servicio de la sociedad. Este servicio lo llevan a cabo las empresas, que son evaluables éticamente en la medida en que son "sujetos sociales". Aquí se considera su finalidad de servicio público en las tres capas durante el confinamiento por el coronavirus.

En el marco de la Ética empresarial, este artículo profundiza en las empresas como "sujetos sociales". Contribuyen de manera decisiva a una realidad de varias capas, que alcanza a la mitad de la población mundial. El análisis de esta Red de redes se realiza a través de la racionalidad y la responsabilidad. Así, este trabajo analiza la responsabilidad ética en ella, basándose en la Ontología social de las empresas y en los problemas éticos según el tipo de racionalidad presente en las empresas — sean micro, meso o macro a tenor de sus metas. Después, desde la perspectiva del servicio a la sociedad, este estudio reflexiona sobre la Ética empresarial en Internet — en sentido amplio — en dos direcciones: 1) la necesidad de una racionalidad evaluativa o racionalidad de fines, pues la racionalidad instrumental o racionalidad de los medios es insuficiente para la Ética, y 2) la importancia de combinar la responsabilidad individual con la responsabilidad social.

Palabras Clave: Internet, Web, la nube, aplicaciones prácticas (apps), "Internet móvil," servicio público, sociedad, Ética empresarial, racionalidad y responsabilidad. 


\section{Theoretical Framework: Companies as "Social Subjects" and the Public Service Purpose}

The Internet - in the broad sense — is today at the heart of the knowledge society, which is at the center of a new historical stage - hyperhistory (Floridi, 2014, 1-24) — and serves that society in many ways. ${ }^{1}$ This network of networks is the main framework for businesses worldwide, which is a new phenomenon that requires analysis from business ethics, with weight on the reflection on rationality and responsibility. The analysis considers the three principal components or layers of this network of networks: 1) the technological infrastructure (or the Internet sensu stricto), 2) the present Web, and 3) the cloud computing, practical applications (apps) and the "mobile Internet." ${ }^{2}$ De facto, large corporations, medium companies and small business firms all have a role in each of the three major layers of this complex system.

Each component listed is, in principle, at the service of society. ${ }^{3}$ According to their structure and dynamics, they can fulfil a social function through companies (micro, meso or macro). This can be a fact, but it can also be a value (specifically, a value that is not only social but also strictly ethical). (i) As a fact, the social function of the three main components of this complex system - the Internet, the Web and the cloud computing, apps, and the "mobile Internet" - can be understood from an instrumental or operational viewpoint. In principle, they carry out their tasks effectively, if not efficiently, ${ }^{4}$ as the Covid-19 crisis has proved. (ii) Considering the social function as a value, then this aspect assumes that it is something worthy of merit — social and even ethical — in the technological infrastructure, the Web or the apps, cloud computing and the "mobile Internet."

1 The Internet comes from an artificial design oriented towards information and communication, which when opened to the public progressively changes social activity and had reached half of the world's population by 2019 (cf. Meeker, 2019).

2 Each of them has its peculiarities in terms of business management, cf. The Economist (2018b, p. 5). On the "mobile Internet" analyzed in the context of prediction, see Yap, Chong, and Liu (2020).

3 This is compatible with recognizing that improper or even harmful use may be made by some organizations or specific agents. Such misuse can be located in the design, in the aims, in the processes or with respect to the expected results.

4 As frequently happens with human designs, the tool can be used for purposes other than those expected, such as social networks and fake news (as has again been seen during the coronavirus epidemic). 
This value would be attributable to companies as social organizations and to the agents working in them.

Within the social function as a fact and as a value of each component or layer, there is then a public service purpose. 1) This is a specific feature of intentionality of the activity performed. ${ }^{5}$ Thus, there is a sought-after purpose that gives meaning to the activity carried out. 2) It involves a disposition towards what is presented as ought to be, so rational decision making looks more towards the optimum, ${ }^{6}$ rather than limiting itself to the routine or mere fulfilment of a task. 3) The public service purpose includes a sense of ethical responsibility within a social context, so the motivation to serve has to do with contributing to the good of a social entity or society as a whole. ${ }^{7}$

This feature of public service purpose of each layer applies to companies whether small, medium or large — insofar as a company can be a "social subject." This approach requires the acceptance of a social ontology, where business firms are considered "subjects" to what are applicable notions such as causes, ${ }^{8}$ reasons and motives. ${ }^{9}$ Accordingly, the characterizations of the theory of social action can be used for companies (cf. Tuomela, 1991, 1996, 2007), but knowing - as Herbert Simon defended - that in these cases the whole - the organization — is more than the sum of the parts (cf. Simon, 1991a).

As a characteristic of a subject, either individual or social, the public service purpose can be something conscious and deliberate. Hence, it involves free human actions and, therefore, an activity that can be evaluated ethically. In this regard, we need then to consider four aspects: a) the ends sought, b) the means used, c) the results obtained, and d) the consequences that follow from these

5 Intention and intentionality are two different concepts, both from the point of view of the social sciences and from the perspective of ethics. Because "intention" is an unobservable mental act, while "intentionality" is a feature of an activity. See von Wright (1983, p. 42). This has a very clear incidence for the philosophical-methodological characterization of prediction in Economics, cf. Gonzalez (2015a, pp. 186-188).

6 Rescher distinguishes between the "optimum," which is what a person can achieve, and the "maximum," which is the limit of the human being. Cf. Rescher (1987).

7 Prima facie, this characteristic favor that, in given circumstances, the public service purpose can be altruistic in ethical terms.

8 On the characteristics of the causes, see Gonzalez (2018a).

9 "Motive" here means that which determines the tendency or choice of a subject, while "intention" looks towards that to which the subject tends or chooses when he or she decides to act (cf. Anscombe, [1957] 1963, p. 18). 
actions. Thus, in the three main layers of the network of networks (the Internet, the Web, and the cloud computing, apps and the "mobile Internet"), the actions of companies can show the characteristics of the public service purpose, which might be a fact and also something assumed as a value. Among the requirements is, first, the need for rationality in selecting ends and means, where evaluative rationality is crucial in order to be of real service; ${ }^{10}$ and, secondly, there should be responsibility in actions, so that the purpose of service to society is truly sought, rather than the preference for maximum profit or an economic return regardless of other parameters.

Historically, when the Internet and the Web started, the public factor prevailed in the service of society, although the recipient of the innovation was just one sector of society (military or scientific). Both Arpanet - the predecessor of the Internet - and the Web were born in public entities for communal purposes. Their originators had a public service purpose. They thought of service to society as the common thread of their contributions. Even today, both Vinton Cerf, a key figure in the Internet (cf. Cerf, 2014), and Tim Berners-Lee, the designer of the Web, ${ }^{11}$ maintain the will to preserve their contributions for the common good.

Thereafter, with the progressive commercialization of the network and the Web, ${ }^{12}$ the "social subject" came to figure primarily in the field of the private sector. A huge diversification then took place, with many new initiatives, such as large corporations, mainly in the technological sector: Google, Apple, Amazon, Microsoft, etc. Commercialization has been increasingly visible in the third layer - the cloud computing, practical applications (apps) and the "mobile Internet" - where the social dimension has been accompanied by scientific creativity and technological innovation (cf. Gonzalez, 2020a).

Now, after several decades of intense development, we are in a position to elucidate philosophically how the Internet - in the broad sense - is at the service of the society. This involves several aspects. I) The fact and the value of the service to society provided by the Internet during coronavirus lockdown.

10 Evaluative rationality deals with ends, cf. Rescher (1988, pp. 92-106).

11 See World Wide Web Foundation (2019).

12 On how the initial idea of an information and communication tool (first for military and then for universities) changed in a strongly commercial Internet (in the broad sense), see Greenstein (2015). 
II) The ethical problems of the three main layers of the Internet considered in two directions: a) ethical responsibility based on the social ontology of business firms, and b) ethical problems according to the kind of rationality involved. III) Business ethics in the Internet looking at rationality and responsibility. On the one hand, this philosophical analysis focuses on the decision-making in business ethics as related to the rationality of ends and to the rationality of means; and, on the other, it pays attention to the decision-making in business ethics as linked to individual and social responsibility.

\section{The Internet at the Service of Society During Coronavirus Lockdown}

As lockdown in several European countries due to the Covid-19 crisis has highlighted, the network of networks has had a clear social function at the service of society as a whole (local, regional, national and international). ${ }^{13}$ This fact has happened in each of its three ontological components (the Internet, the Web and the cloud computing and apps), which are the successive layers of its structure as a complex system. ${ }^{14}$ Initially, service to society appears on the technological platform - or the Internet as such — insofar as gives support to the other layers. Then the service in the Web - with its multitude of social networks - and in the cloud and manifold practical applications (apps) (cf. The Economist, 2018b, p. 5).

Furthermore, this service to society is also a value, which is appreciated at the micro, meso and macro levels of the configuration of this network of networks. This is recognized by the social agents in the various situations: (i) individuals and small groups; (ii) medium enterprises and regional organizations; and (iii) large corporations and national and international organizations. ${ }^{15}$ Many of the benefits of using the network of networks during the lockdown of the coronavirus epidemic in each country have been short-term. But what has been learned

\footnotetext{
13 The lockdown experiences of the various countries during Covid-19 have characteristics of a "social experiment:" they allow a comparison in terms of objectives, processes and results. The consequences are what is derived from what was done in each case.

14 "The Internet was designed in a layered fashion" (Clark, 2018, p. 37).

5 Multi-agent organizations are designed to deal with global problems. From an operational viewpoint, they function as an agent that articulates teleological, interactive, autonomous, adaptive... Cf. Floridi (2014, 180-181).
} 
in the isolation generated by regulations to deal with the international pandemic may have medium- to long-term effects (e.g., for online learning). These experiences will be especially important if another situation of such strong social vulnerability occurs again.

First, the technological platform serves as the basis for the complex information and communication system. This technological support configures what, strictly speaking, is the layer of the Internet. This includes two types of services to society: I) an Internet Infrastructure Provider [IIP] (cf. Clark, 2018, p. 145), which is the background technological network that allows the worldwide connection of users (individuals, groups, organizations, corporations, governments, transnational bodies, etc.), and II) the Internet Service Provider (ISP), which is the company that connects users to the general technological network.

Both provide an unquestionable service to society, because they constitute the basis by which we can use the network of networks for any other social activity: economic, professional, cultural, educational, etc. These two main components of the technological facet (IIP and ISP) have been key to being able to perform tasks during lockdown due to Covid-19. Certainly, the companies in both cases provided a service that avoided the complete isolation of many people and allowed interpersonal communication and teleworking. In this sense, these companies contributed de facto to social cohesion. In the second case, the Information and Communication Technologies (ICT) of the users promoted the sociality of individual confined agents and allow management (economic, social, cultural, etc.). ${ }^{16}$

It is certainly a type a service that has an economic component, which is justifiable in terms of the search for a common good (that is, something of a general nature that benefits each of the users). ${ }^{17}$ These companies provide a service to social life, but their activity is not driven by genuine acts of altruism, either in

\footnotetext{
16 Network traffic has been so intense in confined countries that the big Internet TV companies (OTT, such as Netflix or HBO) have had to lower the quality of their broadcast, to leave bandwidth for other tasks. In the case of lockdown in Spain, the average is 79 hours per week attached to the screen, according to Nielsen 'Digital Consumer 24 hours Indoor' report in collaboration with Dynata, cf. Hi-Retail (2020).

17 It is understood that the "common good" adds social and anthropological nuances to the notion of "public interest." Cf. Douglass (1980) and Simm (2011).
} 
the ethical sense of the word ${ }^{18}$ or in other possible usages. ${ }^{19}$ Thus, although the service can be used to carry acts of solidarity between individuals, groups or organizations, the origin of the service does not seem to be focused on solidarity from the outset. ${ }^{20}$

Second, the Web played a key role in Covid-19 lockdown for many reasons (social, educational, economic, cultural, etc.) and has contributed to a sense of community while the public isolate. Historically, this layer was designed on 12 March 1989 by Tim Berners-Lee with a mind of public service purpose, because he wanted to achieve a fluid communication among the large number of CERN researchers. But the name he gave his design - WorldWideWeb, which was initially one word - (cf. Hendler, forthcoming $)^{21}$ highlighted that he wanted it to be at the service of the whole of society. Since then the Web has had a spectacular development, which has expanded in each of the new versions (2.0. 3.0, etc.) [Hendler and Golbeck, 2008] and, in addition, has given rise to the science of the Web (Hendler and Hall, 2016; and Hall, Hendler, and Staab, 2016).

Through the Web - during the public restrictions due to the diffusion of the Covid-19 — we have been able to reach almost all aspects of social life: a) economic information and management (many forms of e-commerce); b) educational activities (through the platforms like Moodle or Google hangouts); c) interpersonal relationships in many ways (mainly through the webmail, social networks, Skype for face to face telephone calls or Microsoft Teams for lecturing on line); d) entertainment and information (by means of audiovisual platforms like YouTube); e) an alternative to television and cinema (with television over

18 Commonly, in the usage that prevails in ordinary language, “ 'altruism' expresses a moral pro-attitude in the speaker. Surprisingly, this aspect of the term has escaped a closer inspection in the existing philosophical literature" (Schefczyk and Peacock, 2010, 177).

19 Philip Kitcher has distinguished several types of altruism, such as biological, within an evolutionary context; psychological, when it is concerned some kind of intentions; and behavioral, which is a type of social behavior (cf. Kitcher, 2010). Previously, Herbert Simon had associated altruism with a type of economic behavior with an evolutionary component of adaptive rationality (cf. Simon, 2005).

20 In experimental economics, an attempt has been made to measure the level of solidarity of participants in games, usually designed for university students (cf. Selten and Ockenfels, 1998). Solidarity is a more intense concept than reciprocity (do ut des) or collaborative action (group cooperation), since it involves donating something of one's own (money, time, etc.) to others without expecting, in principle, feedback or measurable benefit (i.e., a specific profit).

${ }_{21}$ When the pages of this paper are cited, they correspond to Hendler's original text. 
top, OTT, in platforms like Netflix, HBO, Movistar+, etc.); f) a source for international, national and local news (with the online newspapers); g) some practical activities of an ordinary type (such as ordering food from companies with home service), etc.

Third, the cloud computing, practical applications (apps) and the "mobile Internet" is a layer that performed a service to society, mainly by their association with a multitude of mobile phones (now $4 \mathrm{G}$ and soon $5 \mathrm{G}$ ). ${ }^{22}$ In this regard, "the word cloud is a bit misleading — it tends to imply something amorphous and indefinite in form. Cloud computing, in its physical manifestation, is anything but indefinite in form - cloud computing platforms can be buildings the size of a football field, housing hundreds of thousands of processors, and drawing (and dissipating) megawatts of power" (Clark, 2018, 301-302). The cloud has one advantage for the service: in addition to relying on the Internet, it also uses other networks that have been developed with the same Internet technology. Thus, "cloud providers use these networks to reach their enterprise consumers, thereby shielding that traffic from various attacks and fluctuations in performance" (Clark, 2018, 307).

Meanwhile, the practical applications or apps "rely on the same web architectures" as web browsing (cf. Hendler and Hall, 2016, 704). Thus, they have had, to a large extent, a social function similar to the Web in terms of service to society, even though many of them have a clear local focus. Within the recent lockdown, some aspects stand out: (i) increased communication through messaging tools such as WhatsApp (owned by Facebook); (ii) a growing use of mobile phones to make payments via electronic banks; (iii) apps offering medical and pharmacological information about Covid-19, where some are clearly altruistic in a social sense; and (iv) free access to apps with cultural content (such as tutorials for learning issues) or oriented towards entertainment activities.

22 One of the relevant aspects from the social point of view is that "Huawei holds many crucial patents on superfast 5G mobile networks" (The Economist, 2019h, 57). 


\section{Companies as "Social Subjects" in the Face of the Internet as a Multilayered Reality}

For the analysis of the service to society of the network of networks, seen from an ethical point of view, we need to consider companies - large, medium or small — as "social subjects" in the face of the Internet — in the broad sense - as a multivariate reality. In this regard, for the characterization of companies as ethical subjects of free human actions, we need to ponder the reality on which they act — the various layers of the network of networks pointed out - ${ }^{23}$ and the limits attributable as subjects in terms of responsibility and rationality. These three principal layers - the Internet sensu stricto, the Web and the manifold applications, cloud computing and the "mobile Internet" — have been developed over the years and they have different goals.

When the focus is on the Internet as a framework for business ethics and the issue of public service purpose, at least two aspects need to be considered: first, its ontological status as a multilayered reality and, second, the goals of the diverse layers. In this regard, the Internet is a complex system (cf. Schultze and Whitt, 2016), both in structural and dynamic terms (cf. Gonzalez, 2018b). Thus, the decision-making concerning its structure and dynamics involves several kinds of rationality: cognitive, practical and evaluative. ${ }^{24}$ The degree of ethical responsibility depends to a large extent on the scale of concentration or decentralization in each layer, i.e., the kind of organization available and its limits. ${ }^{25}$ Hence, when the complex structure of the Internet receives an ethical analysis, rationality and responsibility have a role:

I) Each layer of the Internet as a complex system — the network, the Web and the manifold applications, cloud computing and "mobile Internet" — can be connected to the diverse levels of ethical elucidation. This can be made according to two main factors: a) the ends sought in each case, which vary in the degree of generality, and b) the means used to reach them. Furthermore, each layer, insofar

23 Ontologically, the Internet was designed with layers (cf. Clark, 2018, 37). The three main layers or tiers mentioned in this paper can be conceived as successive in dynamic terms, but not necessarily as dependent in terms of their structure.

24 These are the main three kinds of rationality from a general perspective, cf. Rescher (1988, 2-3).

25 China's Internet is already the most centralized by far. It has been considered "a perfect example of a Hamiltonian internet for maximum control” (The Economist, 2018c, 9). 
as it is a human design, includes aspects of cognitive, practical and evaluative rationality, which are relevant for aims, processes and results. The type of service provided and the possible public service purpose of the companies depends on the type of activity of each layer, since on the technological platform it is much more impersonal than in the social networks of the Web or in specific practical applications (apps).

II) Normally, for both design and development, each layer comes from a free human activity of a collaborative kind. But it can also be a competitive activity, within the company or with respect to another. There is ordinarily responsibility of the individuals, groups and organizations that have developed those designs, which can vary greatly in terms of the designers' commitment to service. In addition, each layer has specific ethical problems to be discussed due to the kind of human activity involved, which can be scientific, technological and social (cf. Gonzalez, 2018c). Some of the ethical problems included in each level of the Internet are related to business ethics. This is especially relevant when it comes to the use of personal data, such as on social networks or in the cloud computing.

Relevant here for the characterization of "social subjects" in terms of ethical evaluation is the external dynamics of the Internet. This dynamic, which is imbued with historicity, ${ }^{26}$ is related to its threefold setting: artificial, natural and social. In the case of the social milieu, the dynamics goes together with the three kinds of relations: (i) between the agents themselves developing the Internet as a whole, (ii) the agents with the organizations, such as companies, providing support for this network of networks, and (iii) the agents with the public in general, which is placed within a historical context.

Ontologically, the artificial component has special weight, both in structural and dynamic terms. The first level or bottom layer is the network as such: the technological infrastructure itself, which is located at the initial level of ethical evaluation. This layer has "all the protocols that allow different sorts of networks and devices to exchange information, or 'internetwork' (hence internet). At that level, it is still largely decentralised: no single company controls these protocols (although the number of firms providing internet access has dropped sharply...)"

26 Historicity is a feature of human design, which together with the artificial component has a social dimension and usually has a link with the natural environment. This historicity unfolds in an internal dynamic and an external dynamic. Cf. Gonzalez (2013b). 
(The Economist, 2018b, 5). ${ }^{27}$ Usually, Internet Infrastructure Provider organizations are large corporations, often from the field of telephone communications, whereas Internet Service Provider organizations may be branches of the former or smaller companies (local, regional or national).

Above the network is located the second layer: the Web. It has changed intensely since 30 April 1993, when "the European Organization for Nuclear Research (CERN) announced that the World Wide Web it had created would be free to everyone" (Floridi, 2014, 18). De facto, the second layer "has become much more concentrated. This is particularly true of the web and other internet applications, which include many consumer services, from online search to social networking" (The Economist, 2018b, 5). The ethical problems are more noticeable in some social networks, such as Facebook, because of the controversy around privacy following the use of personal data by Cambridge Analytica. ${ }^{28}$

On top of the network and the Web is the third layer, where all the extensions of the Internet have been spawned, including online commerce and banking. To some extent, there is a clear centralization due to the technological mediation to reach the expected aims. In this regard, a small number of companies have a large part of the sales, insofar as "most people use one of two smartphone operating systems: Apple's iOS or Google's Android. Cloud computing is a three-horse race among Amazon, Google and Microsoft" (The Economist, 2018b, 5). All the apps, the smartphone operating systems and cloud computing are located at this layer, where the Internet is now hugely commercial. Moreover, it is particularly useful for practical purposes and is also a source of ethical issues (such as those related to privacy and information security).

27 "In the 1990s America's telecoms industry was split between two rival factions. On the one side were the 'bellheads', name after the former telephone monopolist, Bell (...). They believed in proprietary technology, vertical monopoly and deference to regulators. Set against them were the 'netheads'. They have grown up with the internet, which is based on 'packet switching': information is digitised, cut into small packets, each routed along the best available connection to the destination, and then recombined. Netheads favoured opensource software, collaboration between firms and decentralised decision-making" (The Economist, 2020, 47).

28 Facebook "had to admit that it had shared the personal data of $90 \mathrm{~m}$ users with outside firms without permission. It late suffered a data breach affecting $50 \mathrm{~m}$ users" (The Economist, 2018d, p. 58). This scandal led to new discussions on the need for new privacy laws, cf. The Economist (2019a). 


\subsection{Ethical Responsibility based on Social Ontology of Business Firms}

Following the three layers of the Internet, there is an ethical responsibility based on the social ontology of companies related to them and their goals. From the viewpoint of the subject of ethical responsibility, these features involve two important aspects: I) there is a difference between "markets" and "organizations," where "the larger part of modern economy's business is done by organizations" (Simon, 1991a, 29); and II) the organizations can be considered ontologically as social subjects, a kind of agent that comes with intentionality in the activity displayed and, therefore, with responsibility insofar as the organization controls the decision-making.

Clearly, the first layer — the network itself — is largely technological. ${ }^{29}$ In this infrastructure for the whole building, the providers are commonly big organizations, corporations such as AT\&T or Verizon. These organizations that build the infrastructure able to carry Internet bandwidth are responsible for the sustainability of the network of networks as well as for the accessibility and security of this technological support. Furthermore, there are the social entities that rule on the protocols (Transmission Control Protocol, TCP; Internet Protocol address, IP; the domain name system, DNS; etc.), such as the Internet Corporation for Assigned Names and Numbers (ICANN). They serve the Internet in the service of society.

Commonly, the responsibility of these organizations is focused on general aims of the network of networks, and their direct responsibility concerns the technological realm. In hindsight, "one of the reasons why the Internet has been successful is that it was designed with the goal of generality. In fact, there are two important aspects of generality represented in the Internet: generality with respect to the applications that run over it and generality with respect to the sorts of communications technologies out of which it can be built" (Clark, 2018, 42).

29 "The Internet is not a specific communications technology such as fiber optics or radio. It makes use of these and other technologies in order to get packets from place to place. A goal of the designers of the Internet was to allow as many communications technologies as possible to be used in the Internet and to incorporate new technologies as they were invented" (Clark, 2018, 6). 
Consequently, there is a very important difference between the network the technological infrastructure of the Internet - and the design of the Web. The network carries protocols (TCP/IP) that are oriented towards communication between machines, whereas the Web was designed by Berners-Lee years later with the aim of communication between people. The World Wide Web Consortium (W3C), which he created in October 1994, standardized many protocols in that direction (cf. Greenstein, 2015, 102). This difference between the network and the Web is particularly relevant from an ethical point, especially in terms of responsibility, because over half of the world's population was connected to the Web by 2019.

Besides the clear difference in the goals between the first and the second layer, where the Web with all its elements has a more visible connection to the social dimension of the Internet (cf. Berners-Lee et al., 2006, 770), the second layer has a stronger repercussion than the network in terms of responsibility concerning processes and results. The controversy between privacy and usability is now constant. This is the case of the use of the webmail (Gmail, Yahoo, Hotmail, Zimbra, Outlook, etc.), when the companies can have actual access to the contents or can make them accessible for some institutions (like the National Security Agency, NSA). Even more clear is the case of the social networks, where the personal information - text, photos and videos — is available and the security is not always guaranteed or well preserved. ${ }^{30}$

Concerning processes and results, the main problems of responsibility in the second layer come with the social networks and official webpages of commercial companies that gather data from users or customers. ${ }^{31}$ In this regard, "data" seems a rather abstract concept, whereas "digital identity" sounds closer to the human agents and, therefore, ethically more serious. Thus, "it is only when 'data' is understood to mean 'people' that individuals will demand accountability from those who seek to know them" (The Economist, 2018e, 14). This has had consequences at least for companies that have suffered some sort of data breach. Just in 2018, there is a long list of well-known companies, which includes "Google, Marriott, Delta, British Airways, Cathay Pacific, Best Buy, Sears, Saks 5th Avenue, even Panera" (The Economist, 2018e, 13).

\footnotetext{
30 In the case of Facebook, the company also runs WhatsApp, Instagram and Messenger. Regarding its new business model thinking of privacy, see The Economist (2019b).

31 From an economic viewpoint, data are primary goods that, when structured as information first, and as knowledge later, are more useful.
} 
As for the third layer, a key aspect is the online commerce, which is commonly supported by an approach based on Artificial Intelligence, ${ }^{32}$ such as learning machines. In this regard, the ethical problems of the apps, the operative systems of the smart phones and cloud computing can be connected with the ethical issues on Artificial Intelligence. This is the case of Amazon, which gets a substantial part of its benefits from cloud computing. A central element of this firm is Amazon Web Services (AWS), because it "underpins Amazon's \$26bn cloud-computing business, which allows companies to host websites and apps without servers of their own. AWS's chief use of machine learning is to forecast demand for computation" (The Economist, 2019e, 55).

Although Amazon cannot see the content hosted in its servers, it can monitor the traffic of its customers, the time used in the connections and how solid these connections are. With these metadata Amazon can "feed machine-learning models which predict when and where AWS [Amazon Web Services] is going to see demand" (The Economist, 2019e, 55). These metadata have a different ethical status from the personal data used in the case of Cambridge Analytica, insofar as they are impersonal tendencies regarding possible preferences instead of actual personal information about private matters, which should have the explicit consent of the individuals affected in order to permit the access to them.

Among the expansions of the Internet - in the broad sense - through this third layer is banking, which is important for digital economics and particularly so for the social dimension of the network of networks. Thus, "in Asia payment apps are a way of life for over 1 bn users. In the West mobile banking is reaching a critical mass - $49 \%$ of the Americans bank on their phones — and tech giants are muscling in. Apple unveiled a credit card with Goldman Sachs on March 25th [2019]. Facebook is proposing a payments service to let users to buy tickets and settle bills" (The Economist, 2019g, 9).

To properly serve society, the three layers require responsibility in the organizations and in the individuals that design them, select their aims, choose their processes and foresee their results, which can lead to expected consequences. As social entities, business firms should consider prudence as an ethical guide for designs, aims, processes and results. Prudence to evaluate future events based on the available information is a kind of auto-regulation, instead of waiting

32 On the difference between human intelligence and Artificial Intelligence, see Gonzalez (2017, 397-424; especially, 404-408). 
for inconvenient events in order to make reasonable decisions (as in the case of Facebook and Cambridge Analytica, a consulting firm) or to receive sanctions because of the institutional regulations (international, national or regional) in place either in terms of defense of competitiveness, protection of the digital copyright or in order to preserve privacy (such as the European Union and Google). ${ }^{33}$ Prudence in the decision making is based on values, which should be considered when the designs are made, the aims are selected, the processes are chosen, and the results are anticipated.

\subsection{Ethical Problems according to the Kind of Rationality Involved}

Given the multilayered reality of the Internet, there are ethical problems related to each layer and connected to rationality in addition to responsibility. Rationality has a role in the decision-making about the network as technological support, in the Web as central part of the virtual world or infosphere - with the enhancement of human possibilities - and in the cloud computing and many apps. In the decision-making of the individuals, groups and organizations, rationality is available in three main forms: a) cognitive rationality, which deals with knowledge; b) practical rationality, which considers human actions; and c) evaluative rationality, which discusses values (cf. Rescher, I988, 2-3).

Thinking about the public service purpose of the network of networks, there are ethical problems related to each one of the three main forms of rationality. I) Regarding the sphere of cognitive rationality, we can see the problems of knowledge society and the companies that need to deal with digital identity and personal data. In this area of privacy, big data comes with big responsibility. ${ }^{34}$ II) Concerning practical rationality, we can consider the right course of action when there is a problem such as a reputational crisis due to breach of confidence, as has happened with the use of Facebook's data by Cambridge Analytica. III) As for evaluative rationality, we can think of the kind of values that we should

\footnotetext{
33 "This week Google was fined $\$ 1.7$ bn for strangling competition in the advertising market. Europe could soon pass new digital copyright laws" (The Economist, 2019c, 11).

34 This is also the case for the Internet of the Things, cf. Harvard Business Review Staff (2014). " $5 \mathrm{G}$ is more than just a faster way to stream Netflix on the go. It enables networks that can support the 'Internet of Things' (IOT)" (The Economist, 2020, 47).
} 
pursue in a business firm in the short, middle and long run in order to have high ethical standards.

Besides the area of management, we can enlarge the scope to ponder other aspects. In the case of cognitive rationality, whose horizon is the search for true statements, we can accept that the use of knowledge through the Internet using ICT involves a distributed responsibility, which depends on the diverse levels of interaction in the processes of decision-making. ${ }^{35}$ In the knowledge society the agents that make decisions on the Internet need to consider the knowledge that comes from three sources: science, technology and society. Each involves an ethical side that can be relevant for the decision-making in a given context.

Also, practical rationality can be related to these sources of knowledge. Business ethics can be connected to applied science, which looks for solutions to concrete problems based on prediction to reach prescription (cf. Gonzalez, 1998), and especially in the application of science, which uses applied knowledge in given contexts and according the circumstances of the situation available (cf. Niiniluoto, 1993; and Gonzalez, 2013a, 11-40; especially, 17-18). Business ethics can be related to technology, because the search for the right thing to do when there is a creative transformation of the reality (natural, social or artificial) is important. Thus, besides the endogenous values of technology, which are related to technological activity as human and free, there are exogenous values of technology that are important for society as a whole (cf. Gonzalez, 2015b).

Actually, the network as such depends to a large extent on big companies that can offer the technological support for this infrastructure of information and communication. The kinds of regulations available are commonly international, even though there are some national or regional regulations. The ethical problems in the first layer are mostly those related to technological issues and ethical values related to engineering. But this clearly reaches the social dimension in the third layer, insofar as social events such as banking are made over the smart phone, where one of the issues is the need for a strong cybersecurity to avoid hacking.

Evaluative rationality, which deals with the foundations, characteristics and possible priorities in the values, can be related to the scientific approach to the

35 "The phenomenon of distributed morality, encompassing that of distributed responsibility, is becoming more and more frequent" (Floridi, 2014, 186). 
Internet, the technological side and the social dimension of the network of networks. Hence, when there is a serious problem in a business firm related to the Internet, such as a noticeable decrease in the level of trust in the company or a full-fledged crisis (as has happened a number of times over the years, at least since "the dot-com bubble" of 2000-2002), the issue of the ethical values of the business firm (like integrity or to be trustworthy) comes into play.

One central problem is then the possible collective responsibility in ethical terms: is there a collective morality on responsibility when a company crashes? One reasonable solution is in tune with Nicholas Rescher's idea of group intentions based on the individuals of that organization. They might be responsible if two coordinated factors are met: (i) the existence of a distributed consensus among the members of the group and (ii) a centralized consent through the representational procedure of the organization for the decision-making (Rescher, 2003, p. 136).

\section{Business Ethics on the Internet}

If "data is the new oil," then the business ethics in the Internet has novelty in at least two ways. I) It is info-ethics, insofar as a substantial part of the business related to the network, the Web or the manifold applications and cloud computing is connected with data, which leads to problems of responsibility about privacy, security, etc. II) There is an expansion of business ethics in this new economic realm, insofar as novel phenomena appear in this human sphere. This virtual world has different characteristics from the social environment (like bitcoin or new financial products). Frequently, these new phenomena are related to economic science (economic theory, applied economics and application of economics) and, thereafter, they depend on the regulations in place (international, national, regional).

Novelty is a central feature of the new economy that comes with the use of the Internet and raises new questions about legitimacy, also from an ethical point of view (cf. Gonzalez, 2020b). This type of novel phenomena can be exemplified in the case of the social networks. Thus, "Facebook's business relies on three elements: keeping users glued to the screens, collecting data about their behaviour and convincing advertisers to pay billions of dollars to reach them with targeted ads" (The Economist, 2018a, 9). This novelty in the virtual world or infosphere 
can be analyzed in terms of rationality of ends and rationality of means as well as from the standpoint of individual responsibility and social responsibility.

\subsection{Rationality of Ends and Rationality of Means}

In order to face the business ethics of the Internet based on rationality, it is necessary to consider the concept of "rationality" used. In this regard, Simon an influential Nobel Prize winner in economics - is well-known for his "bounded rationality," which he developed as an alternative to classical and neoclassical conceptions of rationality. However, he was able to present three models of human thinking: first, the administrative decision maker; second, the universal decision maker, based on the approach to homo economicus; and third, the symbolic problem solver, the conception related to cognitive psychology and Artificial Intelligence (cf. Dasgupta, 2003; and Gonzalez, 2007a).

Initially, Simon focused his analysis on the rationality of the administrative decision maker. This was when he was a member of the prestigious Cowles Commission. ${ }^{36}$ Then he moved towards the rationality of the universal decision maker (Simon, 1957, 198), ${ }^{37}$ which is related to the rationality of the homo economicus. Thereafter, he broadened his views on rationality with the symbolic problem solver, which is used in The Sciences of the Artificial (Simon, 1996), where cognitive psychology converges with Artificial Intelligence. This volume includes the idea of economics as a science of design, and is open to two models of thought: a) the universal decision maker and b) the symbolic problem solver.

Administrative rationality appears in the social dimension of the Internet, insofar as there is a public intervention of governments in the network of networks, such as in the case of the discussion on Huawei and the US government regarding the $5 \mathrm{G}$ mobile technology for smart phones (cf. The Economist, 2019f). Economic rationality has a clear role in the three layers of the Internet, and is more noticeable in the second and the third. This is the case of the social networks (Facebook, Snapchat, Instagram, LinkedIn, etc.) and the manifold applications, such as the apps of an increasing number of companies and cloud

36 In the Cowles Commission for Research in Economics worked some of the most influential economists of the twentieth century, see Simon (1991b, 101-102).

37 On the history of the concept of "bounded rationality," see Klaes and Sent (2005). 
computing. Symbolic rationality is connected to Artificial Intelligence. Thus, although Simon's vision of AI is no longer the dominant view, ${ }^{38}$ it seems clear that Artificial Intelligence has a very important role in many companies related to the Internet, such as Google - as a search engine or in its service "translate" — or in the new developments in the third layer related to big data.

These three types of rationality involve a different kind of ethical responsibility. But the question here is the characterization itself of "rationality" that Simon uses and which underlies the three approaches mentioned. His view on rationality as purely instrumental — completely focused on means - has a very clear philosophical limitation, which directly affects the conception of ethics of human actions, in general, and to the characterization of business ethics, in particular. Because he maintains that "we see that reason is wholly instrumental. It cannot tell us where to go; at best it can tell us how to get there. It is a gun for hire that can be employed in the service of whatever goals we have, good or bad" (Simon, 1983, 7-8). Insofar as he conceives reason in these instrumental terms - just focused on means - his conception of rationality in any of the three forms mentioned — administrative, economic and symbolic — involves restrictions for ethical evaluations.

Moreover, Simon actually excludes any chance for an evaluative rationality or rationality regarding ends, because he defends that "rationality can only go to work after final goals are specified; it does not determine them" (Simon, 1995, 60). Following this mere instrumental reason, he does not offer an examination of the validity or not of the goals sought. But this trait seems to be very relevant, especially when there are ethical problems concerning conflicting goals or when the economic agents need to think about the goals themselves. Obviously, the search for economic maximization through the pursuit of merely private interests and the search for cooperative, altruistic or solidary goals in a business firms can have a role in the evaluation of an action.

What Simon has proposed is reason conceived as bounded by the situation and by human computational powers. His behavioral model, which is an alternative to subjective expected utility of the neoclassic economics, uses instrumental reason to make adaptive choices and sometimes survives in a complex world (cf. Simon, 1983, 34). His view can describe actual behavior in the business firms, whereas ethics ponders what ought to be. Thus, his conception includes several

38 On Simon's view of AI and the role of bounded rationality, cf. Gonzalez (2007b). 
ethical problems, insofar as this approach has resemblances with David Hume's idea of reason exclusively linked to means (cf. Hume, [1739-1740] 1964, book II, part iii, sect. 3):

(i) When there is decision-making, the economic agent needs to consider that it is reasonable to evaluate the ends sought. An evaluative rationality can inform us that certain preferences are absurd (i.e., preferences against our nature or clearly diminishing our chances) and establishes priorities regarding the ends (cf. Rescher, 1988, 92-106). Thus, evaluative rationality can inform us about the adequacy of the ends sought regarding the accepted ethical values (such as the public service purpose for a better society), which can lead the economic agent towards what is preferable rather than towards what is merely preferred.

(ii) Human decision-making cannot be reduced to a rationality that depends exclusively on the "process" itself that generated it (cf. Simon, 1976, 131). The mere efficacy or efficiency in the means used by the economic agent does not guarantee that the action performed is rational in ethical terms. What is correct or not in a human action goes beyond a pure instrumental reason leading towards "given goals." Thus, to get things done is not the same as to do the right things. This is the basis for regulations, which is an increasingly relevant factor for the Internet, especially in the layer of the Web, as well as in the layer of the apps, cloud computing and the "mobile Internet."

\subsection{Individual Responsibility and Social Responsibility}

Regulations are, in principle, an expression of social responsibility. They can have an endogenous origin, when the business firms make explicit the rules that should guide their activity, or an exogenous origin, when the rules come from another institution (international, national, regional, ...), which can impose sanctions if the rules are not followed. Both cases include the existence of two kinds of limits of an ethical evaluation: a) the boundaries, which establish what is within the realm of the activities of the companies, and b) the confines, which reckons the frontiers regarding the future events.

What seems to be in between the two initial options is when individuals who are leaders in their technological firms related to the Internet, like Mark Zuckerberg or Tim Cook, ask for regulations from international or national 
institutions. Thus, the CEO of Facebook has "urged the world's governments to regulate social networks. Specifically, he wants to protect the public from harmful content (such as videos of massacres), ensure the integrity of elections, guarantee that users can move their data between services, and underwrite user's privacy" (The Economist, 2019d, 55). Meanwhile, the CEO of Apple considers that regulations are needed in order to avoid great damage to society (cf. Liao, 2019). These views seem to be in tune with Europe's General Data Protection Regulation, which has been in place in the European Union since May 25th 2018 (GDPR, 2016).

Besides the individual responsibility of the leaders of their companies, there is the individual responsibility of the designers and of the users of the three layers of the Internet, insofar as there is a bi-directional or two-way relation and a strong interaction between the internal and the external sides of the network of networks; which is clear in the second and third layer. An interesting case is the Web, which has provided an infrastructure for many business firms since it became open to the public in general. Since 1993, the Web is, to some extent, in our hands as its users.

Social responsibility can be conceived as "collective responsibility" as Rescher does. ${ }^{39}$ This requires group intentions in the case of coordinated productions, where responsibility must initiate with the intentions of the individuals. Thus, groups or an organization can attain the condition of being responsible "by derivation" from those that belong to that collective, via some consensus or through a delegated consent. Accordingly, a collective responsibility of a group or an organization "exists only with coordinated group products produced under conditions of a synthesis of individual intentions via consensus or delegation. Then and only then is it proper to project group responsibility onto its component individuals - and only to the extent that their intentions were causally involved" (Rescher, 2003, 136). ${ }^{40}$

Pondering the future of Web - the confines — in terms of both individual and social responsibility, there are a number of values to be preserved, such as privacy, security, accessibility or mobility. The side of its internal developments

\footnotetext{
39 Social responsibility from the perspective of science and technology-related professions is discussed in Shrader-Frechette (2005, pp. 51-79).

40 On the relations between economics, ethics and policy, see also Hausman et al. (2016) and Khosrowi (2019).
} 
includes the semantic web, the presence of intermodal elements or the new services designed for the Web; and the side of the external contributions involves interaction with the Web, new demands for the designers, new things thought of, browsers, wikis, blogs, data integrators, etc. Thus, individual responsibility and social responsibility are intertwined now and in the future.

Looking at the future of the Web, Hendler highlights three central elements to understand it: (i) how privacy is understood, since personal data are increasingly present in various Web applications; (ii) the political component, which depends on the desire of governments to control relevant information on the Web and, where appropriate, deny access to the Web to others; and (iii) the decentralization or possible fragmentation of the Web, due to the large companies or the national interests of some governments (cf. Hendler, forthcoming, $5-8)$.

Based on these key elements, Hendler sees three possible scenarios for the future of the Web: 1) the negative or dystopian, if negative trends take the lead over the Web; 2) the positive or open, if free market criteria prevail, democratic systems and transparency of information; and 3) the intermediate between both, which has features of both, and which seems the most likely (cf. Hendler, forthcoming, 8-12). All these have consequences for the companies related to the Web and for society as a whole.

\section{Coda: Final considerations}

Prima facie, ethical commitments go beyond the laws and this is particularly important in the case of the Internet at the service of society. In addition, a key issue is what kind of ethical commitments can be accepted for the business ethics. This certainly affects companies — whether micro, meso or macro — related to the layer of the Internet, the Web and the cloud, practical applications (apps) and the "mobile Internet." This relevant issue depends on a number of factors, including the following:

(i) If the intentionality of human activity is accepted as a key notion for the public service purpose, which requires evaluate rationality and the acceptance of responsibility in a social environment; (ii) if we can reach some ethical values 
that can be objective and, therefore, can have a general character; ${ }^{41}$ (iii) if a central point of the ethical values is the openness to the persons (individuals and groups), ${ }^{42}$ rather than the emphasis on the consequences of the behavior observable; (iv) if responsibility is assumed in terms of prudence in the decision-making and common good, rather than in terms of legal constraints (that obviously should be respected); and (v) if practical rationality is connected to cognitive rationality and evaluative rationality, where human rationality in business cannot be reduced to instrumental rationality (focused on the means) and needs to consider evaluative rationality, in order to select the ends according to values and establish priorities for the decision-making in human activity regarding business. ${ }^{43}$

\section{Acknowledgments}

This paper has been written within the framework of the research project FFI2016-79728-P supported by the Spanish Ministry of Economics, Industry and Competitiveness (AEI). Part of this text is based on the paper "Internet as a Framework of Business Ethics: Rationality and Responsibility," which I presented at the Congress of the European Business Ethics Network (EBEN) held in Valencia in June 2019. A further development of some of the ideas set out here can also be found in my paper "Electronic Economy, Internet and Business Legitimacy," first published online - in August 2020 - and shortly after in print by Springer in the book edited by J. D. Rendtorff: Handbook of Business Legitimacy: Responsibility, Ethics and Society. DOI: https://doi.org/10.1007/978-3-319-68845-9_84-1.

41 On objectivity of values, see Rescher (1999, 73-96).

42 This also leads to better economic results: "Most meta-studies have found that companies with better environmental, social and governance records improved their financial performance" (The Economist, 2019i, p. 53).

43 The ends can be situated in the immediate, short, medium, long and very long term (cf. Gonzalez, 2015a, 66). This modulates the responsibility of companies as social subjects in the decision-making, which includes preventing possible harm. 


\section{References}

Anscombe, G. E. M. ([1957] 1963). Intention, Oxford: B. Blackwell, 1957; 2nd ed., 1963 (reprinted in 1976).

Berners-Lee, T., Hall, W., Hendler, J., Shadbot, N. and Weitzner, D. J. (2006). "Creating a Science of the Web", Science, 313 (5788), pp. 769-771.

Cerf, V. G. (2014). "Knocking Down Strawmen”, IEEE Internet Computing, 18 (6), pp. 88-88.

Clark, D. D. (2018). Designing an Internet, Cambridge, MA: The MIT Press.

Dasgupta, S. (2003). "Multidisciplinary creativity: The case of Herbert A. Simon", Cognitive Science, 27 (5), pp. 683-707.

Douglass, B. (1980). "The Common Good and the Public Interest", Political Theory, 8 (1), pp. 103-117.

Floridi, L. (2014). The Fourth Revolution - How the Infosphere is Reshaping Human Reality, Oxford: Oxford University Press.

GDPR (2016). "General Data Protection Regulation", Official Journal of the European Union, v. 59, May 4th 2016, pp. 1-88. Available in https://gdpr-info.eu Accessed on 19.11.2019.

GonZalez, W. J. (1998). "Prediction and Prescription in Economics: A Philosophical and Methodological Approach" Theoria, 13 (32), pp. 321-345.

Gonzalez, W. J. (2007a). "Análisis de las Ciencias de Diseño desde la racionalidad limitada, la predicción y la prescripción." In: Gonzalez, W. J. (ed.), Las Ciencias de Diseño: Racionalidad limitada, predicción y prescripción, A Coruña: Netbiblo, pp. 3-38.

Gonzalez, W. J. (2007b). "Configuración de las Ciencias de Diseño como Ciencias de lo Artificial: Papel de la Inteligencia Artificial y de la racionalidad limitada." In: Gonzalez, W. J. (ed.), Las Ciencias de Diseño: Racionalidad limitada, predicción y prescripción, A Coruña: Netbiblo, pp. 41-69.

Gonzalez, W. J. (2013a). "The Roles of Scientific Creativity and Technological Innovation in the Context of Complexity of Science." In: Gonzalez, W. J. (ed.), Creativity, Innovation, and Complexity in Science, A Coruña: Netbiblo, pp. 11-40.

Gonzalez, W. J. (2013b). "The Sciences of Design as Sciences of Complexity: The Dynamic Trait." In: Andersen, H., Dieks, D., Gonzalez, W. J., Uebel, Th. and Wheeler, G. (eds.), New Challenges to Philosophy of Science, Dordrecht: Springer, pp. 299-311. 
Gonzalez, W. J. (2015a). Philosophico-Methodological Analysis of Prediction and its Role in Economics, Dordrecht: Springer, 2015.

Gonzalez, W. J. (2015b). "On the Role of Values in the Configuration of Technology: From Axiology to Ethics.” In: Gonzalez, W. J. (ed.), New Perspectives on Technology, Values, and Ethics: Theoretical and Practical, Boston Studies in the Philosophy and History of Science, Dordrecht: Springer, pp. 3-27.

Gonzalez, W. J. (2017). "From Intelligence to Rationality of Minds and Machines in Contemporary Society: The Sciences of Design and the Role of Information," Minds and Machines, 27 (3): pp. 397-424. DOI: 10.1007/s11023-017-9439-0.

Gonzalez, W. J. (2018a). "Configuration of Causality and Philosophy of Psychology: An Analysis of Causality as Intervention and its Repercussion for Psychology." In: Gonzalez, W. J. (ed.), Philosophy of Psychology: Causality and Psychological Subject. New Reflections on James Woodward's Contribution, Boston/Berlin: De Gruyter, pp. 21-70.

Gonzalez, W. J. (2018b). “Complejidad dinámica en Internet como plataforma de información y comunicación: Análisis filosófico desde la perspectiva de Ciencias de Diseño y el papel de la predicción," Informação e Sociedade: Estudos, 28 (1): pp. 155-168.

GonZalez, W. J. (2018c). "Internet en su vertiente científica: Predicción y prescripción ante la complejidad," Artefactos, 7(2), 2nd period: pp. 75-97. DOI: http://dx.doi. org/10.14201/art2018717597.

Gonzalez, W. J. (2020a). "La dimensión social de Internet: Análisis filosóficometodológico desde la complejidad," Artefactos: Revista de Estudios sobre Ciencia y Tecnología, 9 (1): pp. 101-129.

Gonzalez, W. J. (2020b). "Electronic Economy, Internet and Business Legitimacy." In: Rendtorff, J. D. (ed.), Handbook of Business Legitimacy: Responsibility, Ethics and Society, Dordrecht: Springer, pp. 1327-1347. DOI: https://doi.org/10.1007/9783-319-68845-9_84-1

Greenstein, S. (2015). How the Internet Became Commercial. Innovation, Privatization, and the Birth of a New Network, Princeton, NJ: Princeton University Press.

Hall, W., Hendler, J., and Staab, S. (2016). “A Manifesto for Web Science @10," December, pp. 1-4. Available at: http://www.webscience.org/manifesto (Accessed on 16.5.2018).

Harvard Business Review Staff (2014). "With Big Data Comes Big Responsibility," Harvard Business Review, November, pp. 101-104.

Hausman, D., McPherson, M. and Satz, D. (2016). Economic Analysis, Moral Philosophy and Public Policy, Cambridge: Cambridge University Press. 
Hendler, J. and Golbeck, J. (2008). "Metcalfe's Law, Web 2.0, and the Semantic Web," Journal Web Semantics: Science, Services and Agents on the World Wide Web, 6 (1): pp. 14-20.

Hendler, J. and Hall, W. (2016). "Science of the World Wide Web," Science, 354 (6313): pp. 703-704.

Hendler, J. (forthcoming). “The Future of the Web.” In: Gonzalez, W. J. (ed.), The Internet and Science: An Analysis from the Structural and Dynamic Complexity.

Hi-Retail (2020). "79 horas a la semana pegados a la pantalla: Así es el confinamiento de los españoles", available at: https://hiretail.es/tendencias/tech/79-horas-a-lasemana-pegados-a-la-pantalla-asi-es-el-confinamiento-de-los-espanoles/ 3.4.2020. (Accessed on 7.4.2020).

Hume, D. ([1739-1740] 1964). A Treatise of Human Nature, ed. L. A. Selby-Bigge, Oxford: Clarendon Press.

Khosrowi, D. (2019). "Trade-Offs Between Epistemic and Moral Values in Evidence-Based Policy," Economics and Philosophy, 35 (1): pp. $49-78$.

Kitcher, P. (2010). "Varieties of Altruism," Economics and Philosophy, 26 (2): pp. 121148.

Klaes, M. and Sent, E.-M. (2005). "A Conceptual History of the Emergence of Bounded Rationality," History of Political Economy, 37 (1): pp. 27-59.

LiaO, S. (2019). "Tim Cook says tech needs to be regulated or it could cause 'great damage to society.' 'We are advocating strongly for regulation — I do not see another path," The Verge, April 23rd 2019. Available at: https://www.theverge. com/2019/4/23/18512838/tim-cook-tech-regulation-society-damage-apple-ceo (accessed on 27.5.2019).

Meeker, M. (2019). Internet Trends 2019. Report published on 11 June 2019, 334 pages. Available in: https://www.bondcap.com/pdfIInternet_Trends_2019.pdf Accessed on 22 July 2019.

Ninniluoto, I. (1993). “The Aim and Structure of Applied Research,” Erkenntnis, 38 (1): pp. 1-21.

Rescher, N. (1987). Ethical Idealism: An Inquiry into the Nature and Function of Ideals, Berkeley, CA: University of California Press.

Rescher, N. (1988). Rationality: A Philosophical Inquiry into the Nature and the Rationale of Reason, Oxford: Clarendon Press.

Rescher, N. (1999). Razón y valores en la Era científico-tecnológica, Barcelona: Paidós. 
Rescher, N. (2003). "Collective responsibility." In: Rescher, N., Sensible Decisions. Issues of Rational Decision in Personal Choice and Public Policy, Lanham, MD: Rowman and Littlefield, pp. 125-138.

SchefczyK, M. and Peacock, M. (2010). "Altruism as a Thick Concept," Economics and Philosophy, 26 (2): pp. 165-187.

Schultze, S. J. And Whitt, R. S. (2016). "Internet as a Complex Layered System." In: Bauer, J. M. and Latzer, M. (eds.), Handbook on the Economics of the Internet, Cheltenham: Edward Elgar, pp. 55-71.

Selten, R. and Ockenfels, A. (1998). "An Experimental Solidarity Game," Journal of Economic Behavior and Organization, 34 (4): pp. 517-539.

Shrader-Frechette, K. (2005). "Objectivity and Professional Duties Regarding Science and Technology." In Gonzalez, W. J. (ed.), Science, Technology and Society: A Philosophical Perspective, A Coruña: Netbiblo, pp. 51-79.

Simm, K. (2011). "The Concepts of Common Good and the Public Interest: From Plato to Biobanking," Cambridge Quarterly of Healthcare Ethics, 20 (4): pp. 554-562.

Simon, H. A. (1957). Models of Man, N. York, NY: J. Wiley.

Simon, H. A. (1976). "From Substantive to Procedural Rationality." In: Latsis, S. J. (ed.), Method and Appraisal in Economics, Cambridge: Cambridge University Press, pp. 129-148.

Simon, H. A. (1983). Reason in Human Affairs, Stanford, CA: Stanford University Press.

Simon, H. A. (1991a). "Organizations and Markets," Journal of Economic Perspectives, 5 (2): pp. $25-44$.

Simon, H. A. (1991b). Models of my Life, Basic Books, N. York, NY, (Later reprinted in Cambridge, MA: The MIT Press, 1996).

Simon, H. A. (1995). "Rationality in Political Behavior," Political Psychology, 16 (1): pp. 45-61.

Simon, H. A. (1996). The Sciences of the Artificial, 3rd ed., Cambridge, MA: The MIT Press (1st ed. in 1969, and 2nd ed. in 1981).

Simon, H. A. (2005). "Darwinism, Altruism and Economics." In: Dopfer, K. (ed.), The Evolutionary Foundations of Economics, Cambridge: Cambridge University Press, pp. 89-104.

The Economist (2018a). “Epic fall," Section Leaders, March 24th 2018, p. 9. 
The Economist (2018b). "More knock-on than network. How the internet lost its decentralised innocence," Special Report: Fixing the Internet, v. 427, n. 9098, June 30th 2018, pp. 5-6.

The Economist (2018c). "The ultimate walled garden," Special Report: Fixing the Internet, v. 427, n. 9098, June 30th 2018, pp. 9-10.

The Economist (2018d). “The new Yahoo?” Section Business: Facebook's future, November 24th 2018, pp. 58-59.

The Economist (2018e). "Les estats, c'est moi. A new way to think about data is needed," Section Leaders, December 22nd 2018, pp. 13-14.

The Economist (2019a). "The Cambridge Analytica bill," Section Tech and Privacy, March 2nd 2019, pp. 41-42.

The Economist (2019b). "Facebook's third act," Section Business: Tech and Privacy, March 9 th 2019, p. 57.

The Economist (2019c). "Europe takes on the tech giants," Section Leaders, March 23rd 2019, p. 11.

The Economist (2019d). "Careful what you wish for," Section Business, April 6th , 2019, p. 55.

The Economist (2019e). "The learning machine," Section Business: AI at Amazon, April 13th 2019, pp. 54-55.

The Economist (2019f). "Communication breakdown. How a giant Chinese telecoms firm became mired in political controversy," Section Briefing Huawei, April 27th 2019, pp. 18-20.

The Economist (2019g). "Tech's ride on the banks," Section Leaders, May 4th 2019, p. 9.

The Economist (2019h). "Technology wars. Inglorious isolation", Section Business, May 25th 2019, pp. 57-58.

The Economist (2019i). "Ask and you shall receive. Why managers should listen to shareholders, Section Bartley, June 1st 2019, p. 53.

The Economist (2020), “Telecommunications: 5Geopolitics," Section Business, April 11th 2020, pp. 47-49.

Tuomela, R. (1991). “The Social Dimension of Action Theory," Daimon, 3: pp. 145158.

Tuomela, R. (1996). The Importance of Us, Stanford, CA: Stanford University Press.

Tuomela, R. (2007). The Philosophy of Sociality: The Shared Point of View, N. York: Oxford University Press. 
von Wright, G. H. (1983). Practical Reason, Ithaca, NY: Cornell University Press.

World Wide Web Foundation (2019). Contract for the Web. A Global Plan of Action to Make our Online World Safe and Empowering for Everyone, November 2019. Available at: https://contractfortheweb.org Accessed on 25.11.2019.

YaP, K. L., Chong, Y. W. AND Liu, W. (2020). "Enhance Handover Mechanism Using Mobile Prediction in Wireless Networks," PLoS One, 15 (1): pp. 1-31. DOI: 10.371/journal.phone.0227982.

Recibido: $10 / 08 / 2020$

Aceptado: 23/11/2020

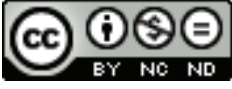

ENDOXA está bajo una licencia de Creative Commons Reconocimiento-NoComercial-SinObraDerivada 4.0 Internacional 